\title{
THE INFLUENCE OF EXTERNAL CLIMATE ON CHURCH INTERNAL MICROCLIMATE
}

\author{
L.BALIK ${ }^{1 *}$, L. KUDRNACOVA ${ }^{1}$ AND K. NEDVEDOVA ${ }^{1}$ \\ Klokner institute \\ Czech Technical University \\ Solinova 7, 16608 Praha 6, Czech Republic \\ e-mail: lukas.balik@cvut.cz, web page: http://www.klok.cvut.cz
}

Keywords: Monument Maintenance, Long-term Microclimate Monitoring, Moisture Regulation

\begin{abstract}
This paper deals with monitoring microclimate in the area of church and describes influence of exterior microclimate to interior microclimate, changes during one year. The basic parameters of the interior space (temperature, relative humidity, dew point and specific air humidity) were monitored in the long-term in the selected sacral building. These parameters were monitored at the same time as monitoring the surroundings in the exterior. The long-term monitoring of the internal microclimate of ossuary showed significant instability of the interior environment during the annual cycle, where the appropriate limits of humidity of the environment (excessive moisture in the spring and over-drying in the winter) are significantly exceeded. The microclimate behavior of ossuary is also different in different height levels, where the lower space acts as a pool with heavy cold air and vice versa, the space under the vault is moistened with vapor. The fact that under no circumstances of the exterior climate in winter is the temperature of the interior below freezing point is specific. The negative phenomenon of the internal environment of ossuary is the fact that in certain periods optimal conditions are created for condensation of water on the surfaces of walls and interior equipment of ossuary and also for the creation of ideal conditions for the formation and development of mold. Monitoring of the internal microclimate of ossuary during everyday operation has become the basis for the subsequent design of the reconstruction of the building. The remediation proposal must address several issues at once. It has to solve the issue of reducing moisture in the peripheral and inner walls of the building, restoring original materials while maximizing their preservation, stabilizing the internal microclimate in terms of humidity, creating optimum conditions for the natural drying of residual structural moisture and, last but not least, ensuring the mode of future operation with minimal effect on changes in the internal microclimate. Due to the historical value of the building and its layout, it is possible to use forced air treatment only to a limited extent, and great emphasis must be placed on addressing this issue by using the natural physical properties of air and phenomena involving its natural flow and controlled temperature exchange between spaces.
\end{abstract}




\section{INTRODUCTION}

The article deals with the results of measurements of the internal microclimate of the ossuary sacral building (church) in Central Bohemia, which serves as a necessary basis for the correct design of a complete reconstruction. The specificity of the ossuary space lies both in the design arrangement and in its operation. From a structural point of view, it is a basement partially recessed below the level of the surrounding terrain, whose perimeter walls are affected by high humidity and there is a high representation of salts. Moisture material degradation can be seen both on plaster walls, as well as on paving and vaults. The internal climate of this space is diverse at individual heights and is very strongly influenced by the way of operation i.e. by the way of ventilation and the presence and movement of excessive amounts of people producing water vapour. Also specific is the internal exhibited inventory, which dominantly forms human historical bones arranged into various clusters and ornaments, and which are distributed practically throughout the whole ossuary space. It is clear that the life span of these bones is fundamentally affected by the environment in which they are found. In the case of ossuary they are currently stored in different environments within one space, and in addition, each environment lives by its specific mode with a different period of change. The remediation designer faces a complex issue that must address the reduction of masonry moisture and related structures, minimizing condensation on indoor surfaces (plaster, paving, stone and wooden elements) while ensuring maximum optimization of the internal microclimate for long-term bone exposure. Optimization of the indoor microclimate consists

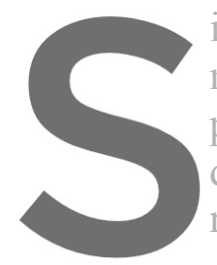
in unifying the paraine minimizing its fundamental che presented long-term ineation abs during its operation reconstruction design [
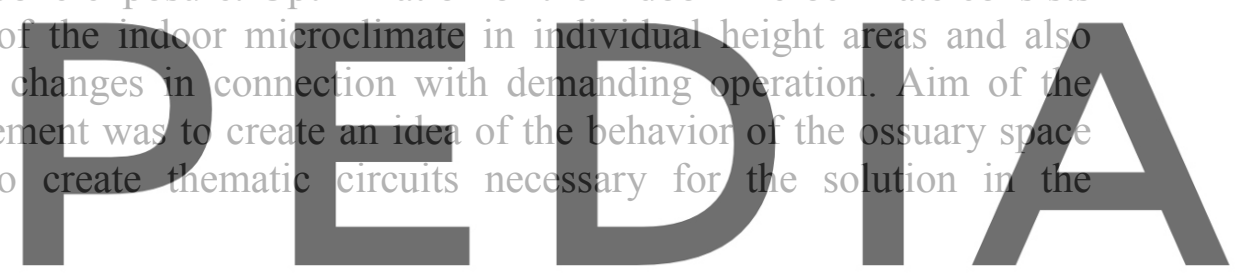

\section{MONITORING DESCRIPTION}

Register for free at https//www.scipedia.com to download the version without the watermark The church itself consists of two chapels. The lower one, which serves as an ossuary, is partially embedded in the ground and carries the upper single nave chapel with presbytery. Several probes were placed in the area of the church in order to monitor the microclimate. The probes were in different height level in order to cover each area of the space.

Long-term measurement of indoor microclimate parameters took place from March 2013 to early April 2017 when the control panel was disconnected. This report processes data obtained from March 2016 to March 2017. The data from the beginning of measurement were described in another paper [2]. Due to unscheduled inputs to measurements caused by various technical interventions carried out in the building, it was not possible to obtain data from all the measured places during the whole measured period but only from shorter (but sufficient for analysis) sections. Data loggers and data logger with probes measuring internal space parameters (temperature, relative humidity and surface temperature) were placed inside of the building [3]. The basic measurements were carried out in the ossuary area and additional measurements were performed in the entrance hall above the staircase (1st floor window), in the chapel (church) above the ossuary and in the roof truss. To make the analysis more precise, the measurements were supplemented by scanning the parameters of the external microclimate (exterior) in the tower area by means of a mounted weather station. For the main 
measurement of the ossuary space was used measuring center collecting data from three probes connected at different height levels. The location of the probes in the area of the object is shown in Fig. 1.

\section{RESULTS OF MEASUREMENT}

The microclimate of the space of the ossuary of the Church of All Saints during the current operation has been showing very high values of internal relative humidity in the long term. The lower parts of the space (the area below the stairs entry landing level) show worse conditions (higher values of relative humidity), as evidenced by the theory of the lower space, which acts as a "closed trap of humid air", which currently has little possibility to escape or circulate. The consequence of this condition causes relatively frequent and long periods of surface condensation of water on cold surfaces (walls, tiles and vaults). This condensation worsens the overall moisture state of the building and radically increases the risk of vegetation of fungi, molds and algae and accelerates the process of natural mechanical degradation of materials (plasters, mortars, stones, bricks, etc.). Based on the results of measurements of indoor microclimate in the premises of ossuary from March 2016 to March 2017, the following basic points can be stated:

- the indoor microclimate of ossuary is highly unstable, which may affect the durability of its structures and movable equipment,

the temperature of the ossuary did not drop below $0{ }^{\circ} \mathrm{C}$ during the frost period,

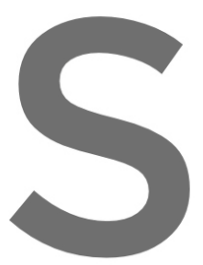

- the average value within $68.6 \% \mathrm{rel}$

up to $26 \%$ of the

reported values

- in terms of water
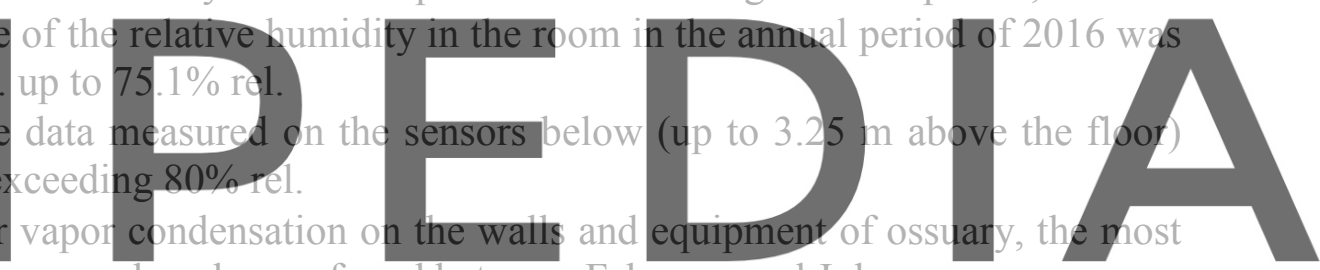

risky period in the annual cycle was found between February and July,

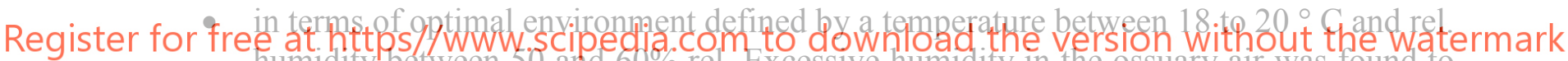
humidity between 50 and $60 \%$ rel. Excessive humidity in the ossuary air was found to be between mid-May and mid-September and, on the contrary, the specific humidity was excessive between November and April. 


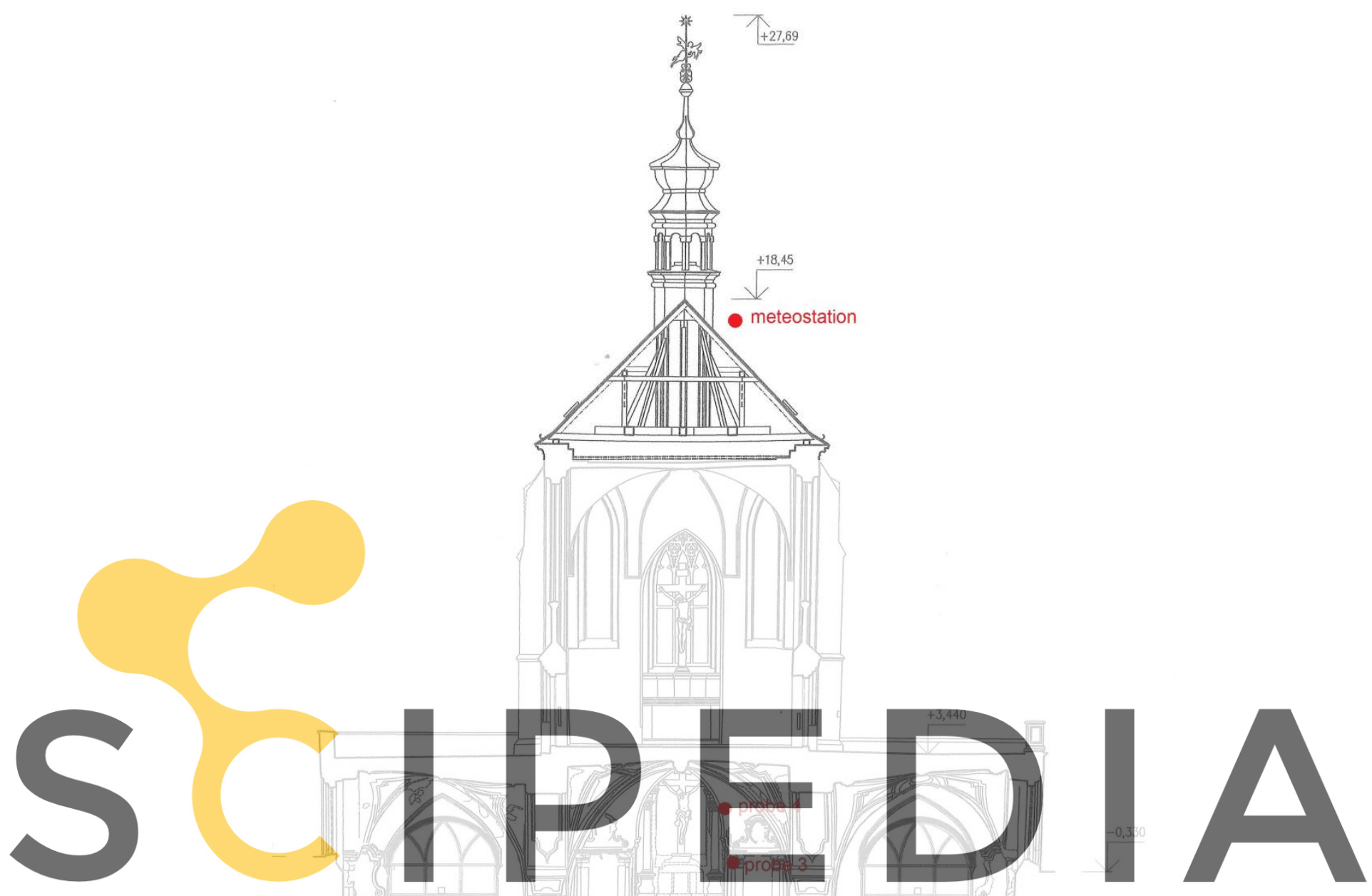

Register for free at https//www.scipedia.com to download the version without the watermark

Figure 1: Drawing of sensor placement in building section.

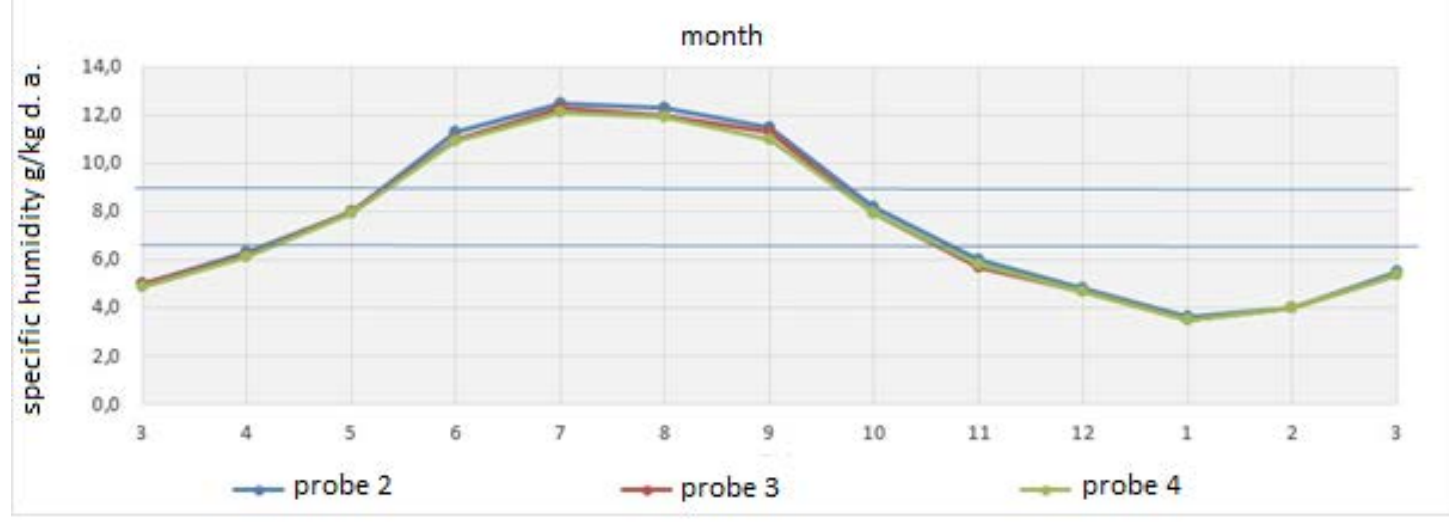

Figure 2: Specific air humidity between March 2016 and March 2017, indicating the boundary areas for $20^{\circ} \mathrm{C}$ 
and $60 \%$ rel. (8.9 g / $\mathrm{kg}$ b.w.) and $18^{\circ} \mathrm{C}$ and $50 \%$ rel. (6.5 g / kg b.w.)

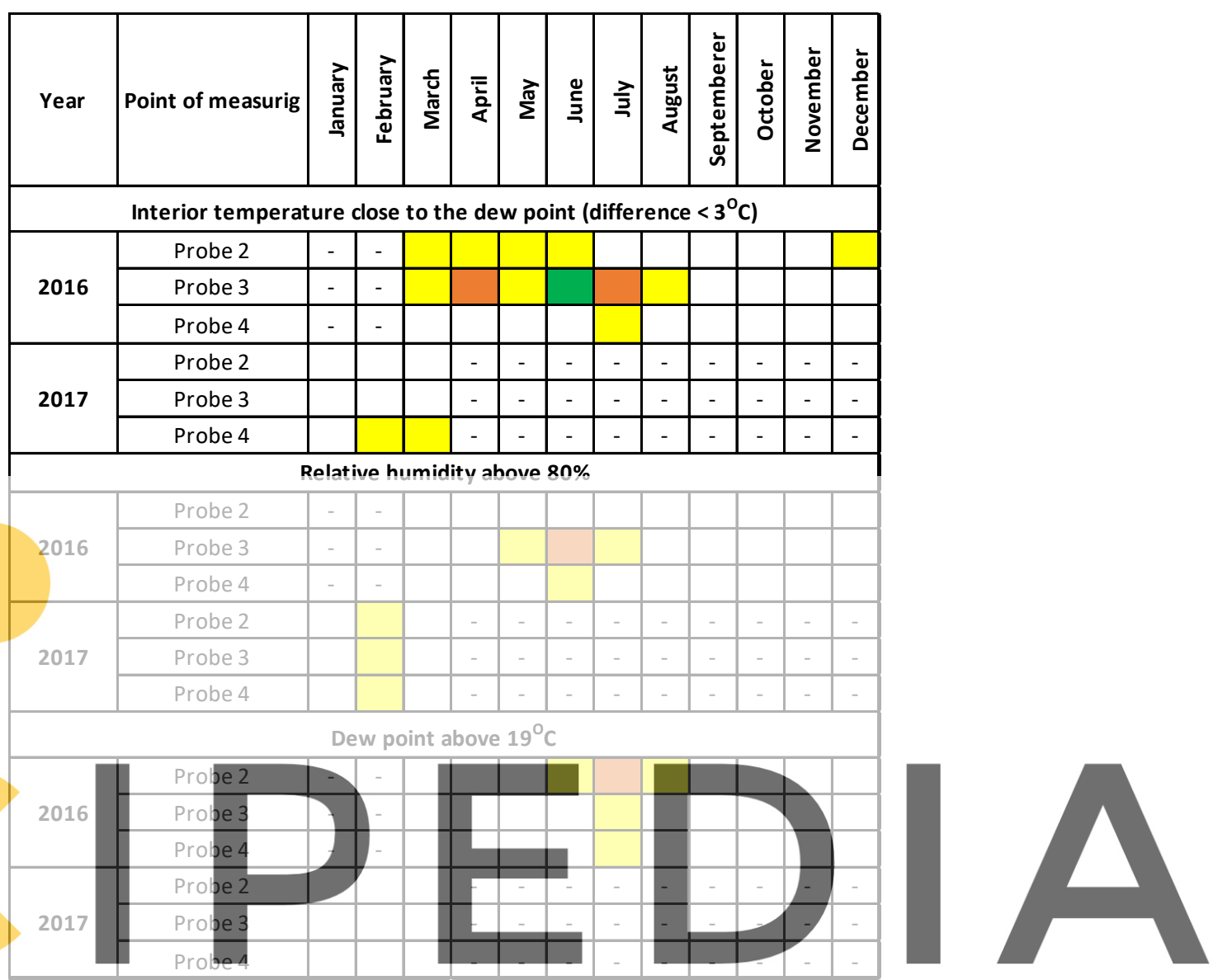

Register for free at https//www.scipedia.com to dewaload the version without the watermark \begin{tabular}{|l|l|}
\hline & up to 10 days during the month \\
\hline & from 10 to 20 days durimg the month \\
\hline & more than 20 days during the month \\
\hline
\end{tabular}

Figure 3: Critical temperature, relative humidity and dew point above $19^{\circ} \mathrm{C}$ in March 2016 to March 2017 


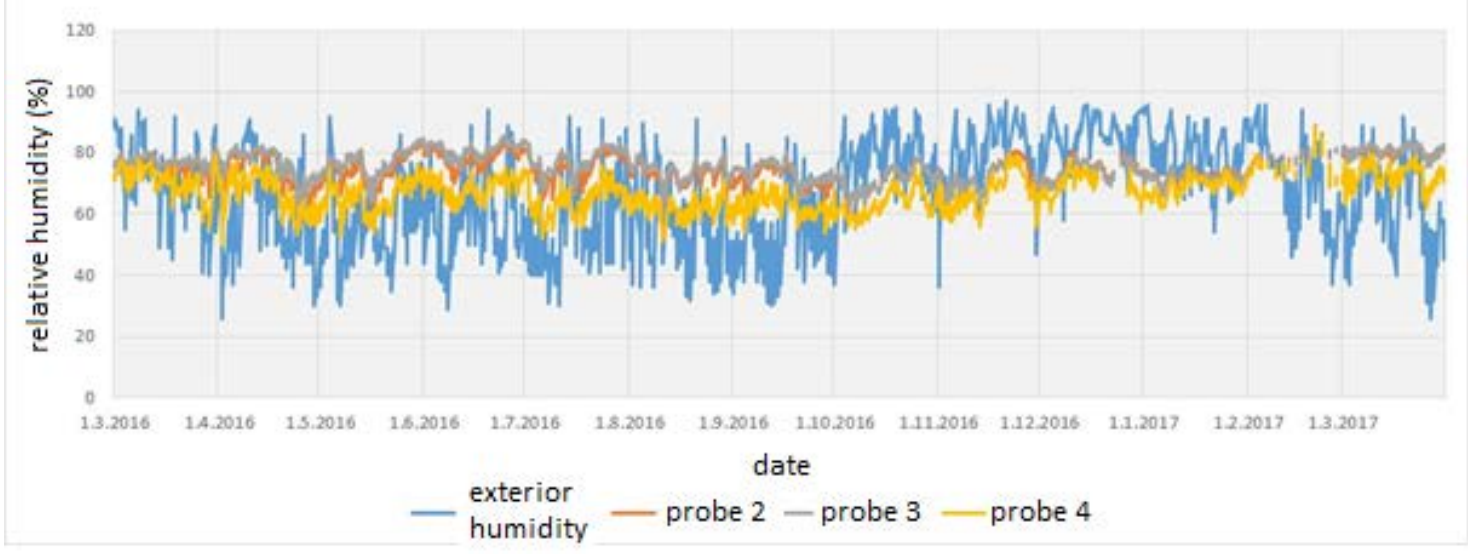

Figure 3: Relative humidity (\%) in exterior (from weather station) compared to relative humidity in interior

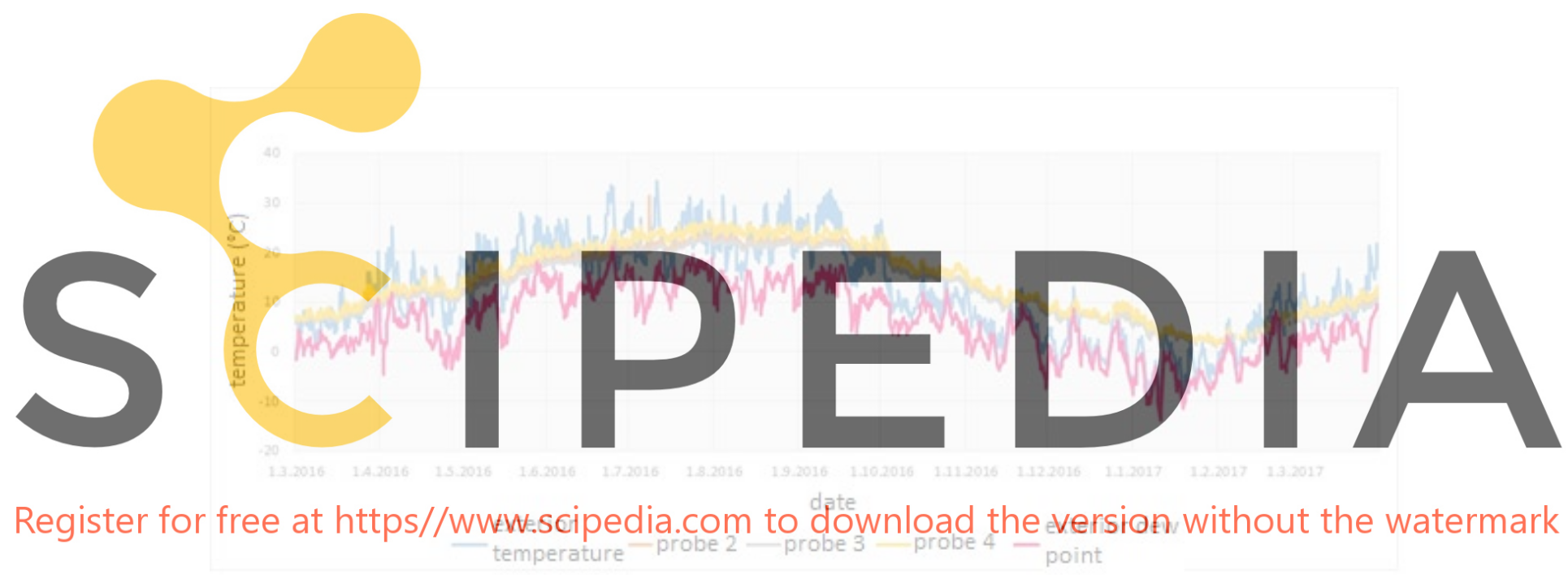

Figure 3: Temperatures $\left({ }^{\circ} \mathrm{C}\right)$ and dew point $\left({ }^{\circ} \mathrm{C}\right)$ of outdoor temperatures (from the weather station) compared to indoor temperatures from March 2016 to March 2017

The causes of the high relative humidity in the ossuary are:

- penetration and long-term retention of humid air from the exterior into the lower situated area of the ossuary without the possibility of proper circulation,

- $\quad$ supplying moisture to the ossuary space from damp walls and floors,

- increase of the relative humidity of the ossuary space caused by the repeated presence of a high number of people.

\section{CONCLUSIONS}

Based on the findings, it is clear that the internal microclimate of ossuary is at some risk when using the space for the purpose it is used today (exposing or storing human bones). The most risky is the instability of the environment, where the specific air humidity changes during the annual cycle and therefore changes in the environmental conditions (temperature, 
relative humidity and specific humidity) in which the bones are stored. The indoor microclimate varies not only with changes in weather during the year, but also shows different values at different height levels of the space. The bones placed in the lower part are in more humid environment than the bones suspended under the ceiling. The solution of indoor microclimate should follow three main points:

- stabilization of the internal microclimate of the ossuary space in time and space,

- ensuring an optimal bone storage environment;

- elimination of the reasons that may cause undesirable fluctuation of indoor microclimate parameters.

Fulfillment of the above points is possible only to a certain "reasonable" level in mater of improving the conditions of the indoor microclimate. By stabilizing the environment and eliminating the effects it is meant to influence the sources of humidity, which increase the relative humidity in the environment. Therefore it was recommended:

- remediation of peripheral masonry in terms of moisture,

- creation of an interruption zone (eg by the construction of a partition or enclosure) in the area of the cash register which interrupts the direct external influence on the internal microclimate of the ossuary,

- creation of the possibility of extracting humid air from the ossuary area (e.g. controlled "discharge" of humid ground air through the crypt to the exterior and controlled removal of water vapor from the vault areas through the upper suction).

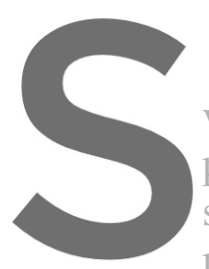

Optimal bone storag ventilation and consu parameters for storage stabilization of the env recommend securing and installing ventilation
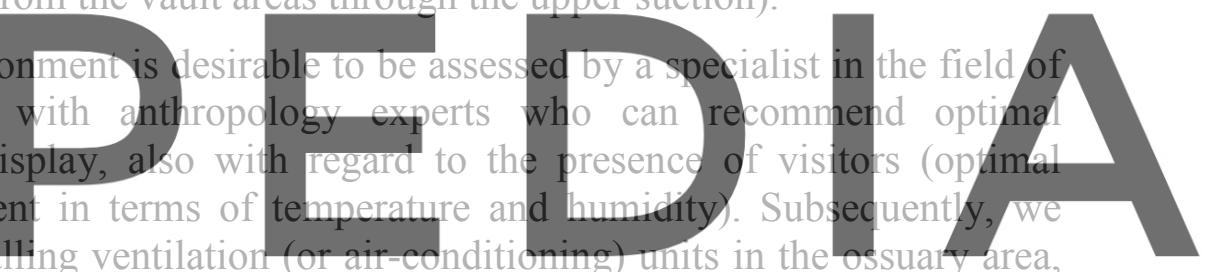
in order to ensure the removal of humid air and to improve the parameters of the largest part

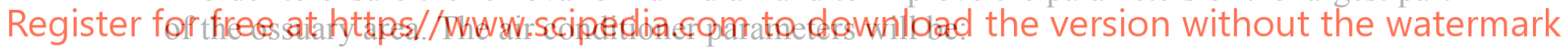

- setting of switching conditions,

- ensuring its establishment and solving the issue of connection to the air iniet and outiet,

- ensuring its adequate capacity, ie the capability of exchanging a specified volume of air over time.

The optimal solution would be adjustable switching of the unit when the defined specific humidity (between 6.5 and $9.8 \mathrm{~g} / \mathrm{kg}$ dry air) is exceeded [4]. Unfortunately, this criterion cannot be evaluated by conventional devices and it is therefore possible to rely at least on a relative humidity sensor. We suggested a value of $60 \%$ rel. If only the use of fans were considered, then the solution would be to reduce rel. humidity in the lower part of the ossuary and its removal e.g. through the floor into the crypt and from there further out. Even in the case of air-conditioning units, the microclimate of the lower part of the ossuary should be addressed, preferably by controlling the microclimate in both directions, too humid and too dry air.

All measures considered must take into account the area from which the air will be pumped and the area (e.g. exterior) where the air will be vented. It is also possible to consider 
a variant where the air extraction units would be supplemented by a separate fan with a sensor and a MaR system, which would supply air from the exterior at a time when the optimum climate in terms of specific humidity will be present. Capacity must be decided by a specialized designer. The basic question is the speed of air exchange throughout the ossuary space and the frequency of switching depending on the space operation.

\section{RESULTS}

The whole measurement led to the finding that there is a different behavior of the microclimate in the individual levels of the ossuary. It was found that there are a number of moments when surface condensation occurs on both plasters and inventory. There is a periodic change in specific humidity in the area, so that in winter low specific humidity prevails, which damages the inventory, and in summer there is excessive specific humidity, which causes the absorption of water vapor into the material and its subsequent degradation. There are sharp changes in the microclimate in the given area, which are harmful in themselves. This worsens already high humidity of the plinth part of the perimeter and internal walls. This resulted in two basic remediation measures for the area:

- material dehumidification of masonry,

- modification of the internal microclimate.

It is necessary to reduce sudden changes in specific humidity and to unify the differences of the microclimate in impividurat condensation to the nax ir large number of visitors will somehow.

All these requirements were
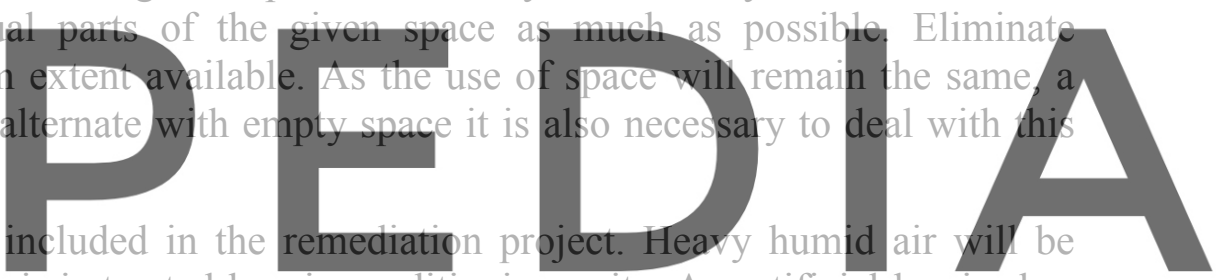

extracted to the outside. The air is treated by air conditioning units. An artificial barrier has

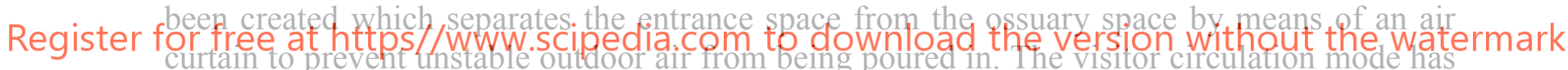

changed by directing the movement of visitors in one direction. They enter through the air curtain into the ossuary in one end and exit elsewhere through the newly built space. That reduced the source of moisture by reducing large concentration of people during ascent and descent into the space.

Acknowledgements. The activity presented in the paper is part of the research grant NAKI II DG18P02OVV012 project of the Ministry of Culture of the Czech Republic.

\section{REFERENCES}

[1] Dorokhov, V. Pintelin, N. Control of Temperature and Humidity Conditions of Church Buildings-Architectural Monuments as a Method of Preservation, 2018 IOP Conf. Ser.: Mater. Sci. Eng. 463032076 
[2] Pavlík, Z., Balík, L. Kudrnáčová, L., Maděra, J. and Černý, R. Chapel of Cemetry Church of All Saints in Sedlec - Long-Term Analysis of hygrothermal Conditions. Thermophysics 2017, AIP, Santa Fe, 2017

[3] Kudrnáčová, L. Balík, L. Sledování mikroklimatu v prostorách kostela. In: Sanace a rekonstrukce 2017, WTA Praha, 2017, p. 71-77. ISBN 978-80-01-06347-7

[4] Černý, M. Němeček, M. Mikroklima v historických interiérech. NPÚ Praha, 2011, ISBN 97880-87104-82-8
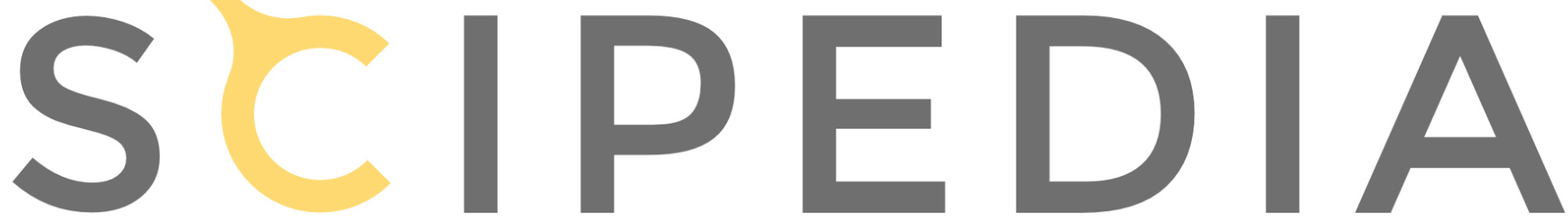

Register for free at https//www.scipedia.com to download the version without the watermark 